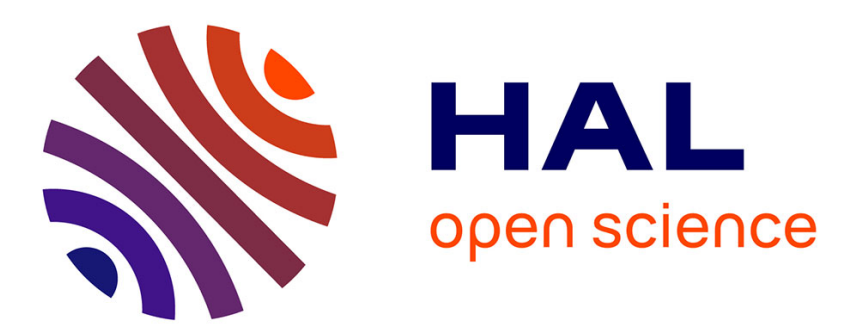

\title{
Magnetostriction of an amorphous (Fe82B18)0.9La 5Tb5 alloy
}

E. Du Tremolet de Lacheisserie, A. Chamberod

\section{To cite this version:}

E. Du Tremolet de Lacheisserie, A. Chamberod. Magnetostriction of an amorphous (Fe82B18)0.9La 5Tb5 alloy. Journal de Physique Lettres, 1983, 44 (24), pp.1013-1016. 10.1051/jphyslet:0198300440240101300 . jpa-00232290

\section{HAL Id: jpa-00232290 https://hal.science/jpa-00232290}

Submitted on 1 Jan 1983

HAL is a multi-disciplinary open access archive for the deposit and dissemination of scientific research documents, whether they are published or not. The documents may come from teaching and research institutions in France or abroad, or from public or private research centers.
L'archive ouverte pluridisciplinaire HAL, est destinée au dépôt et à la diffusion de documents scientifiques de niveau recherche, publiés ou non, émanant des établissements d'enseignement et de recherche français ou étrangers, des laboratoires publics ou privés. 
Classification

Physics Abstracts

$75.50 \mathrm{~K}-75.80$

\title{
Magnetostriction of an amorphous $\left(\mathrm{Fe}_{82} \mathbf{B}_{18}\right)_{0.9} \mathbf{L a}_{5} \mathbf{T b}_{5}$ alloy
}

\author{
E. du Tremolet de Lacheisserie \\ Laboratoire Louis Néel, CNRS-USMG, 166 X, 38042 Grenoble Cedex, France
}

and A. Chamberod

Département de Recherches Fondamentales, Section Physique du Solide, 85X, 38041 Grenoble Cedex, France

(Reçu le 30 août 1983, accepté le 2 novembre 1983)

\begin{abstract}
Résumé. - On donne les variations thermiques des magnétostrictions spontanée et forcée d'un alliage amorphe $\left(\mathrm{Fe}_{82} \mathrm{~B}_{18}\right)_{0,9} \mathrm{La}_{5} \mathrm{~Tb}_{5}$. A la température ambiante, la magnétostriction est un ordre de grandeur plus faible que la valeur prévue, ce qui ôte à cet alliage tout intérêt en tant que transducteur magnétostrictif. La variation thermique de $\lambda_{\mathrm{s}}$ s'interprète assez bien dans le modèle à un ion des ferrimagnétiques.

Abstract. - The thermal variations of the spontaneous and forced magnetostriction of an amorphous $\left(\mathrm{Fe}_{82} \mathrm{~B}_{18}\right)_{0.9} \mathrm{La}_{5} \mathrm{~Tb}_{5}$ alloy are given. The room temperature magnetostriction is one order of magnitude smaller than the predicted value, which disproves the potential interest of this alloy as a magnetostrictive transducer. The thermal variation of $\lambda_{s}$ is well described by the one-ion model for ferrimagnets.
\end{abstract}

The room temperature magnetostriction of amorphous $\mathrm{Tb}_{x} \mathrm{Fe}_{1-x}$ films is known to be large, namely $\lambda \sim 3 \times 10^{-4}$ near $x=0.4[1,2]$, thus indicating the terbium magnetoelastic coupling to be strong in these amorphous alloys as previously found in the crystalline compounds.

Assuming this large magnetoelastic coupling to hold true also in the dilute terbium alloys, Koon and Das have predicted a magnetostriction as large as $\lambda \sim 190-240 \times 10^{-6}$ for the amorphous $\left(\mathrm{Fe}_{82} \mathrm{~B}_{18}\right)_{0.9} \mathrm{~Tb}_{5} \mathrm{La}_{5}$ alloy which they have found to exhibit soft magnetic properties [3]. Such performances would have designated this alloy as an interesting magnetoelastic tranducer, but it remained to experimentally confirm this large magnetostriction.

\section{Experiment.}

The samples were prepared by the standard melt spinning techniques. The ribbons were approximately $1.8 \mathrm{~mm}$ in width, $40 \mu \mathrm{m}$ thick and only a few centimeters long due to their relative brittleness. X-ray diffraction data are given in figure 1 and the alloy appears to be amorphous, if one neglects a tiny signal at $2 \theta=34^{\circ}$ on the upper face of the ribbon. The magnetic properties we observed agree with the data previously given in $[3,4]:$ the magnetization has been measured up to $20 \mathrm{kOe}$ below room temperature by the extraction method, and the low coercivity $\left(H_{c}<\right.$ $3 \mathrm{Oe}$ at $300 \mathrm{~K}$ ) confirms the amorphousness of the sample. At low temperatures, the coercive 


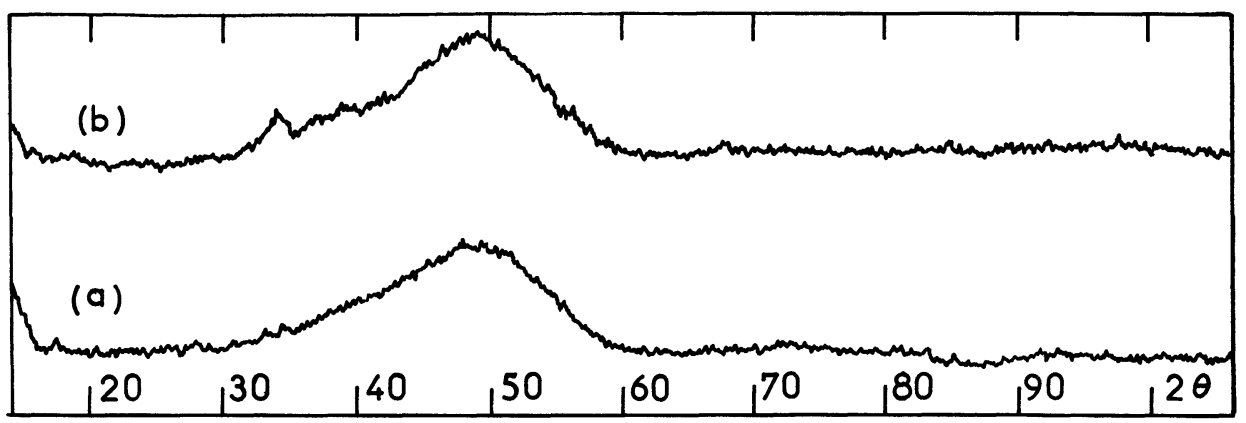

Fig. 1. - X-ray diffraction spectrum of the As-quenched $\left(\mathrm{Fe}_{82} \mathrm{~B}_{18}\right)_{0.9} \mathrm{La}_{5} \mathrm{~Tb}_{5}$ alloy : (a) lower face, $(b)$ top surface. Cobalt anticathode : $\lambda=1.7903 \AA$.

force increases up to $H_{\mathrm{c}}=50 \mathrm{Oe}$ at $4.2 \mathrm{~K}$. Finally, the Curie temperature $T_{\mathrm{c}}=495 \mathrm{~K}$ that we derived from the forced magnetostriction in figure 2 is slightly higher than $486 \mathrm{~K}$, the value given in [4], and this reveals a small difference in the chemical composition, the amorphous $\mathrm{Fe}_{82} \mathrm{~B}_{18}$ alloy without any rare earth having a much higher Curie temperature, $T_{c}=636 \mathrm{~K}$ [5].

The magnetostriction could not be measured by the cylinder method [6] due to the poor mechanical properties, so we piled up 22 pieces about $10 \times 1.8 \mathrm{~mm}^{2}$ in area, $40 \mu \mathrm{m}$ in thickness that we glued together with $\mathrm{M}$ bond 600 adhesive from micromeasurements in order to get a bulk sample according to Tsuya's method [7]. The strains were measured along the larger dimension with a capacitance dilatometer, the magnetic field being applied parallel and then perpendicular to the measurement direction, always in the plane of the ribbons.

The thermal variations of both the spontaneous and the forced magnetostrictions are given in figure 2 for the As-quenched alloy.

\section{Discussion.}

The room temperature magnetostriction we observe is one order of magnitude smaller than the one predicted by previous authors [3], and this can explain the soft magnetic properties of this alloy which no longer offer outstanding technical interest as a magnetostrictive transducer. The analysis of the thermal variation of the magnetostriction can bring further information concerning the magnetoelastic coupling of the terbium in this alloy.

O'Handley [8] first recognized the magnetostriction of amorphous $\mathrm{Fe}_{80} \mathrm{~B}_{20}$ alloy to follow a one-ion law, and this behaviour appeared to be common to most amorphous alloys, see e.g. figure 5 in [9]. In the present case, the alloy is a ferrimagnet and the one-ion law no longer involves the macroscopic magnetization $M_{\mathrm{tot}}=M_{\mathrm{Fe}}-M_{\mathrm{Tb}}$, but is a linear combination (Eq. 1) involving the reduced magnetizations of both sublattices, as already pointed out by Callen et al. [10] :

$$
\lambda_{\mathrm{s}}(T)=\lambda_{\mathrm{Fe}} \hat{I}_{5 / 2}\left[\mathcal{L}^{-1}\left(m_{\mathrm{Fe}}\right)\right]+\lambda_{\mathrm{Tb}} \hat{I}_{5 / 2}\left[\mathcal{L}^{-1}\left(m_{\mathrm{Tb}}\right)\right]
$$

In this equation, we have neglected the thermal variation of the Lamé coefficient $\mu$, since this approximation has already proved to be valid for a lot of metallic glasses.

We have assumed that the iron magnetization varies as the magnetization of the amorphous $\left(\mathrm{Fe}_{82} \mathrm{~B}_{18}\right) \mathrm{La}_{10}$ alloy, the thermal variation of which has been given in [4]. The terbium magnetization has been derived by subtracting the iron magnetization from the magnetization of the amorphous $\left(\mathrm{Fe}_{82} \mathrm{~B}_{18}\right)_{0.9} \mathrm{~Tb}_{5} \mathrm{La}_{5}$ alloy, the thermal variation of which has also been given in [4] and confirmed in this work up to $300 \mathrm{~K}$. The best fit of equation 1 and figure 2 is obtained with $\lambda_{\mathrm{Fe}}=$ $+40 \times 10^{-6}$ and $\lambda_{\mathrm{Tb}}=+16 \times 10^{-6}$. 


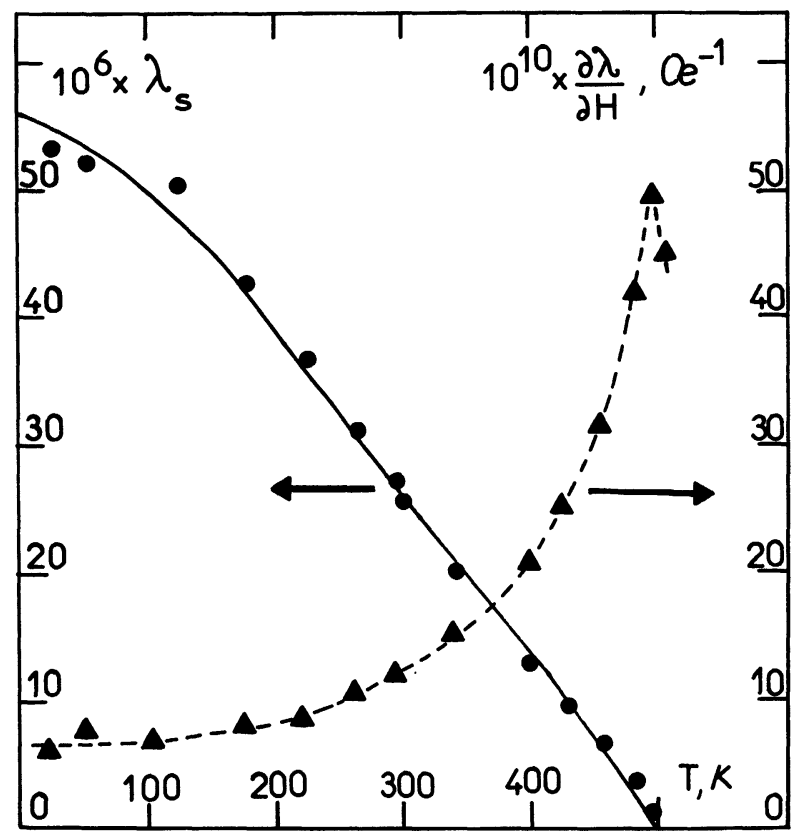

Fig. 2. - Thermal variations of the spontaneous magnetostriction $\lambda_{s}(\bullet)$ and the forced magnetostriction $\partial \lambda / \partial H(\Delta)$ of the As-quenched $\left(\mathrm{Fe}_{82} \mathrm{~B}_{18}\right)_{0.9} \mathrm{~Tb}_{5} \mathrm{La}_{5}$ alloy. The full line illustrates the one-ion prediction of Eq. 1 with $\lambda_{\mathrm{Fe}}=40 \times 10^{-6}$ and $\lambda_{\mathrm{Tb}}=16 \times 10^{-6}$.

The iron contribution must be compared with the data obtained with the amorphous $\mathrm{Fe}_{82} \mathrm{~B}_{18}$ alloy [5], namely, $\lambda_{\mathrm{s}}=46 \times 10^{-6}$ at $0 \mathrm{~K}$. $\lambda_{\mathrm{s}}$ is known to vary roughly as the square of the magnetization for metallic glasses and, taking into account the reduction by $10 \%$ of the number of iron atoms in $\left(\mathrm{Fe}_{82} \mathrm{~B}_{18}\right)_{0.9} \mathrm{La}_{10}$, we predict $\lambda_{\mathrm{Fe}} \sim 25 \times 10^{-6}$ which is a satisfactory value if one considers the above approximations.

On the other hand, the terbium contribution appears very small with respect of the magnetoelastic coupling of $\mathrm{Tb}$ in amorphous $\mathrm{TbFe}_{2}$ [1]. At $300 \mathrm{~K}, \lambda_{\mathrm{s}} \approx 300 \times 10^{-6}$ for this alloy while the $\mathrm{Tb}$ contribution in our alloy is only $4 \times 10^{-6}$ at the same temperature, where $\hat{I}_{5 / 2}\left|\mathcal{L}^{-1}\left(m_{\mathrm{Tb}}\right)\right| \sim 0.25$, which gives one order of magnitude smaller when referring to one $\mathrm{Tb}$ ion.

But, we must notice that the magnetoelastic behaviour of the amorphous series $\mathrm{Tb}_{\boldsymbol{x}} \mathrm{Fe}_{1-x}$ is not linear. For $x=0.05$, the magnetostriction is only $20 \times 10^{-6}$ [1], leading to a negligible contribution of $\mathrm{Tb}$ if one subtracts the iron contribution, and so it is not surprising to find a rather small magnetostriction in the present work.

As a conclusion, the magnetostriction of the amorphous $\left(\mathrm{Fe}_{82} \mathrm{~B}_{18}\right)_{0.9} \mathrm{~Tb}_{5} \mathrm{La}_{5}$ is mainly due to the iron contribution. The magnetoelastic coupling of terbium seems to be smaller in dilute alloys than it is in the composition $\mathrm{TbFe}_{2}$. The thermal variation of $\lambda_{\mathrm{s}}$ is well described by the one-ion ferrimagnetic model of Callen.

\section{Acknowledgments.}

It is a pleasure to thank R. Perrier de la Bathie (CNRS) and J. P. Pezzetti (CENG) for the preparation of the samples and A. Lienard(CNRS) for the X-ray study. 


\section{References}

[1] Forester, D. W., Vittoria, C., Schelleng, J., Lubitz, P., J. Appl. Phys. 493 (1978) 1966-8.

[2] Takagi, H., Tsunashima, S., Uchiyama, S., Funil, T., Jpn. J. Appl. Phys. 182 (1979) 399-400.

[3] Koon, N. C., Das, B. N., Appl. Phys. Lett. 3910 (1981) 840-2.

[4] Koon, N. C., Das, B. N., Geohegan, J. A., Forester, D. W., J. Appl. Phys. 533 (1982) 2333-4.

[5] O'Handley, R. C., Narasimhan, M. C., Sullivan, M. D., J. Appl. Phys. 503 (1979) 1633-5.

[6] Du Tremolet de Lacheisserie, E., Revue Phys. Appl. 18 (1983) 727.

[7] Tsuya, N., Arai, K. I., Shiraga, Y., Masumoto, T., Phys. Lett. A 51 (1975) 121.

[8] O'Handley, R. C., Phys. Rev. B 18 (1978) 930.

[9] Du Tremolet de Lacheisserie, E., J. Magn. Magn. Mat. 25 (1982) 251-70.

[10] Callen, E., Clark, A. E., Desavage, B., Coleman, W., Callen, H. B., Phys. Rev. 1305 (1963) 1735-40. 